\title{
ADIPONECTIN ADDED INTO THE PLASMA OF HEALTHY PROBANDS DOES NOT AFFECT PLATELET AGGREGABILITY
}

\author{
David Stejskal*, Jitka Proskova, Pavlina Solichova
}

\author{
Department of Laboratory Medicine, Sternberk Hospital, Czech Republic \\ e-mail:david.stejskal@quick.cz
}

Received: February 7, 2006; Accepted: April 3, 2006

Key words: Adiponectin/Antithrombotic effect/Platelet aggregability

\begin{abstract}
Six healthy non-obese probands without medical therapy and history of disease were tested. In all of them platelet aggregability with addition of human recombinant adiponectin in different concentrations (100; 75; 50 and $25 \mathrm{ng} / 1)$ were measured. It is concluded that increased level of adiponectin has no significant antiaggregation effect on platelets from individuals without hypoadiponectinemia.
\end{abstract}

\section{INTRODUCTION}

Adiponectin differs from most adipose tissue-produced proteins by decreased production in the obese and insulin-resistant individuals ${ }^{1}$. The most important effects of adiponectin are stimulated phosphorylation of AcetylCoA carboxylase, stimulated oxidation of free fatty acids, stimulated metabolism of glucose and lactate, reduction of gluco-neogenetic enzymes activity, improved effectiveness of insulin, inhibition of local growth factors effects of smooth muscle cells, production of some cytokines, etc. in most of body tisseus . Thus, adiponectin exhibits important antidiabetic and antiatherogenic effects (the term of adipovascular axis is used). Adiponectin may be a new marker of metabolic control in persons with a high risk of atherosclerotic complications ${ }^{1,2}$.

Although hypoadiponectinemia is associated with obesity-related metabolic and vascular diseases, the role of adiponectin in thrombosis remains elusive. A recent paper informed that adiponectin deficiency in adiponectin knockout male mice leads to enhanced thrombus formation and platelet aggregation ${ }^{3-7}$.

The aim of present our study was to evaluace the effect of exogenous adiponectin on platelet aggregability in blood plasma.

\section{METHODS}

Six healthy nonobese probands (30-35 years of age, body mass index of 22-26), without medical therapy and history of disease were tested. In all of them adiponectin concentration in blood serum was assayed by means of an ELISA kit (Biovendor, Czech Republic) and platelet aggregability in blood plasma was measured according to the protocol described below. All examined subjects gave their informed consent according to the Helsinki Declaration and entered the study.
Venous whole blood samples were collected under standard conditions: in the morning, after 12-hour fasting, from non-retracted arm, using a transfusion needle. The first $5 \mathrm{ml}$ of blood collected was discarded for adiponectin measurement. Additional samples were collected into tubes containing $0.5 \mathrm{ml}$ of sodium citrate (concentration of sodium citrate was $3,8 \%$; ratio of sodium citrate and blood $1: 9$ ) and processed within one hour of collection. Whole blood samples were centrifuged for 15 minutes at $100 \mathrm{~g}$ to obtain platelet-rich plasma (PRP) containing $250 \pm 50 \times 10^{9} / 1$ platelets. Platelet-poor plasma (PPP) containing $<7 \times 10^{9} / 1$ platelets was obtained by centrifugation of the remaining specimen at $2000 \mathrm{~g}$ for 15 minutes.

Human recombinant adiponectin (RD172023100; Biovendor; Czech Republic) was added to PRP in different concentrations (100; 75; 50 and $25 \mathrm{ng} / \mathrm{l}$; adiponectin was dissolved in saline solution).

Subsequently, the PRP samples were preincubated for 5 min at $25^{\circ} \mathrm{C}$ and the aggreghation of platelet was started by adition of cationic propylgallate (CPG; Analytical Control Systems, Fishers, Indiana, USA) into a final concentration of $3 \mu \mathrm{mol} / 1$. The aggregometric curves were recorded on the platelet aggregometer Apact II (Labitec, Ahrensburg, Germany). The extent of CPG-induced platelet aggregation was defined as the slope of the aggregometric curve.

\section{RESULTS}

Neither of tested probands had significat difference of the slope CPG values, even if $100 \mathrm{ng} / 1$ adiponectin concentration was added (Table 1). 
Table 1. The extent CPG-induced platelet aggregation in blood plasma samples before and after the addition of adiponectin.

\begin{tabular}{|c|c|c|c|c|}
\hline & \multicolumn{4}{|c|}{ Slope of the CPG-induced platelet aggregation } \\
\hline Addition of adiponectin (nq/1) & Mean & SD & Median & Normality \\
\hline 0.0 & 76.0 & 20.6 & 69.0 & Yes \\
\hline 25.0 & 69.3 & 5.0 & 70.1 & Yes \\
\hline 50.0 & 76.3 & 10.8 & 71.0 & Yes \\
\hline 75.0 & 79.9 & 12.2. & 74.9 & Yes \\
\hline 100.0 & 71.0 & 12.6 & 72.0 & Yes \\
\hline
\end{tabular}

The mean slopes of the CPG-induced platelet aggregation in blood plasma samples before and after the addition of adiponectin were not significantly different $(\mathrm{p}<0.05$, unpaired parametric $t$ test $)$

Normality - normality of data distribution

CPG - cationic propylgallate

\section{CONCLUSIONS}

The present study did not confirm the hypothesis about the in vitro human hyperadiponectinemia as an antithrombotic factor. Adiponectin concentration of about $10 \mathrm{ng} / \mathrm{l}$ has similar antithrombotic in vitro action as values up to $100 \mathrm{ng} / \mathrm{l}$.

\section{REFERENCES}

1 Stejskal D, Ruzicka V, Adamovska S, Jurakova R, Proskova J, Jedelsky L, Bartek J (2003) Adiponectin concentrations as a criterion of metabolic control in persons with type 2 diabetes mellitus? Biomed Pap Med Fac Univ Palacky Olomouc Czech Repub, 147, 167-172
2 Winzer C, Wagner O, Festa A, Schneider B, Roden M, BancherTodesca D, Pacini G, Funahashi T, Kautzky-Willer A (2004) Plasma adiponectin, insulin sensitivity, and subclinical inflammation in women with prior gestational diabetes mellitus. Diabetes Care, 27, 1721-1727.

3 Kato H, Kashiwagi H, Shiraga M, Tadokoro S, Kamae T, Ujiie H, Honda S, Miyata S, Ijiri Y, Yamamoto J, Maeda N, Funahashi T, Kurata Y, Shimomura I, Tomiyama Y, Kanakura Y (2006) Adiponectin acts as an endogenous antithrombotic factor. Arterioscler Thromb Vasc Biol, 26, 224-230.

4 Kumada M, Kihara S, Sumitsuji S (2003) Association of hypoadiponectinemia with coronary artery disease in men. Arterioscler Thromb Vasc Biol 23, 85-89.

5 Matsuda M, Shimomura I, Sata M (2002) Role of adiponectin in preventing vascular stenosis. The missing link of adipo-vascular axis. J Biol Chem 277, 37487-37491.

6 Shimada K, Miyazaki T, Daida H (2004) Adiponectin and atherosclerotic disease. Clin Chim Acta 344, 1-12.

7 Stefan N, Stumvoll M (2002) Adiponectin-its role in metabolism and beyond. Horm Metab Res 34: 469-474. 